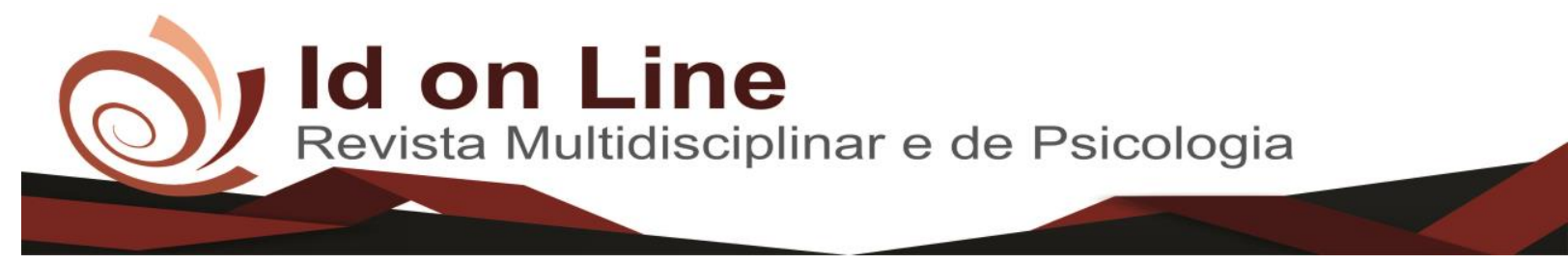

Artigo

\title{
Comportamento do Consumidor: Um estudo sobre Fidelização com Marcas de Café na Cidade de Milagres-CE
}

\author{
Rangiel Santos Bento Silva ${ }^{1}$; Márcia Maria Leite ${ }^{2}$
}

\begin{abstract}
Resumo: Na complexidade do consumo humano, as empresas buscam concomitantemente formas de fidelizar os clientes por meio da satisfação das necessidades e desejos destes, porém o comportamento do consumidor exerce descaminho na hora da compra. Assim, o presente artigo tem por objetivo avaliar através de um teste cego a relação de fidelidade do cliente com uma marca de café na cidade de Milagres-CE. A pesquisa é de natureza quantiqualitativa de cunho experimental. Foi realizado um teste cego com 07 marcas de café, utilizando uma amostragem por acessibilidade e conveniência. Os instrumentos para coleta de dados aconteceram por intermédio de um questionário, composto por 05 perguntas fechadas e 02 abertas. Ao término do teste, aconteceu a análise dos dados para a mensuração dos resultados obtidos. Como resultado, verificou-se que os consumidores conhecem a marca de café produzida na cidade de Milagres-CE, porém não há fidelização a esta, levando em consideração que a qualidade apresentada pelo produto não está condizente com as expectativas dos clientes.
\end{abstract}

Palavras-Chave: Marketing. Comportamento do Consumidor. Fidelização. Teste Cego.

\section{Consumers Behavior: A Study on Fidelization with Coffee Brands in the City of Milagres in the Ceará State}

\begin{abstract}
In the complexity of the human consumption, the companies look for concomitantly loyalty forms the customers through the satisfaction of the needs and desires of these, however the consumer's behavior exercises misplaced in the hour of the purchase. Like this, the present article has for objective to evaluate through a blind test the relationship of the customer's fidelity with the mark of coffee in the city of Miracle-CE. The research is of qualitative nature of experimental stamp. A blind test was accomplished with 07 marks of coffee, using a sampling for accessibility and convenience. The instruments for collection of data happened through a questionnaire, composed by 05 closed questions and 02 open. At the end of the test, the analysis of the date happened for the measurement of the obtained results. At result, was verified that the consumers know the mark of coffee produced in the city of Miracle-CE, however there is at the loyalty the this, taking into account that the quality presented by the product is not in keeping with the customers' expectations.
\end{abstract}

Keywords: Marketing. Behavior of the Consumer. Loyalty. Blind Test.

\section{Introdução}

Na plenitude do mercado contemporâneo, os clientes são movidos por necessidades e desejos para comprar, consumir e descartar produtos ou serviços diariamente, consistindo esta ação, desde os

\footnotetext{
${ }^{1}$ Graduando em administração, Centro Universitário Doutor Leão Sampaio, Juazeiro do Norte, Ceará, Brasil. Contato: rangielsantos10@gmail.com

${ }^{2}$ Especialização em gestão estratégica de pessoas, Centro Universitário Doutor Leão Sampaio, Juazeiro do Norte, Ceará, Brasil. Contato: marcialeite@leaosampaio.edu.br
}

779 Id on Line Rev. Mult. Psic. v.12, N. 42, p. 779-796, 2018 - ISSN 1981-1179
Edição eletrônica em http://idonline.emnuvens.com.br/id 
primórdios com a revolução industrial, acessão do capitalismo, avanços das tecnologias e expansão da globalização (PETRONIUS, 2016). Houve uma evolução na forma do ser humano consumir, oriunda com as turbulências competitivas entre organizações e dos novos hábitos consumistas das pessoas, proferindo concepções, ideias e comportamentos no mercado ao decorrer do tempo (LIMEIRA, 2017).

Os clientes estão projetados a comprar produtos em função da marca, superando preço e qualidade, segundo uma publicação no jornal O Globo de 2017. De acordo com esta matéria publicada as empresas buscam concomitantemente uma conexão com o consumidor, na busca por fidelização, porém o cliente possui comportamentos que exercem descaminhos na hora da compra. Diante do pressuposto, o que leva um cliente a ser fiel a determinada marca?

Para responder esta problemática, este artigo objetiva de modo geral avaliar através de um teste cego a relação da fidelidade do cliente com uma marca de café na cidade de Milagres-CE. Especificando em estudar as bases conceituais do comportamento do consumidor, descrever satisfação e fidelidade do cliente no processo de compra e analisar se o cliente compra um produto em função da qualidade ou marca.

$\mathrm{O}$ artigo justifica-se pelo interesse pessoal em conhecer como clientes reconhecem o café que consomem sem a influência da marca e sim pela qualidade, averiguando aceitação de uma marca produzida na cidade em estudo, mesurando o grau de fidelidade a esta. Contempla importância social por possibilitar aos comerciantes da cidade de Milagre-CE, noções sobre o mercado consumidor de café, permitindo criação de estratégias para captar clientes para este segmento. Em termos acadêmicos, justifica como fonte de pesquisa aos futuros leitores das áreas administrativas que emanam conhecer melhor sobre o assunto em tese, destacando valor científico, visto que não há muitas publicações a respeito do teste cego entrelaçado com o comportamento de consumidor.

\section{Fundamentação Teórica}

\section{Marketing}

O marketing é definido como uma filosofia criada para promover e fornecer bens e serviços condizentes a realidade dos consumidores, na perspectiva de atender as necessidades e desejos destes, por meio da satisfação e promoção de vendas no mercado (KOTLER, 2013).

Na concepção de Samara e Morsch (2012) o consumidor é definido como indivíduo, grupos ou organizações dotadas de necessidades e desejos a serem satisfeitas, desempenhando diferentes funções 
no processo da compra, uso e descarte de bens ou serviços. As autoras apontam que é essencial compreender a mente do cliente, entendendo o que este almeja, sonha e repudia, facilitando ao gestor agir no mercado, seja fidelizando, investindo em novas possibilidades de negócios ou vencendo a concorrência, salientando que esta função contribui efetivamente no sucesso da empresa ao inserir bens apropriados para satisfazer os clientes.

Para Limeira (2017) existem diferenças entre necessidade e desejos, ambas são intrínsecas ao ser humano, no entanto, necessidade é um estado de carência, privação ou sensação daquilo que é essencial para a existência humana, decorrentes ao longo da vida, exemplificando, fome, sede, frio, calor, status, higiene, limpeza, prazer, emoção ou fantasia, contudo o desejo é um estado psicológico direcionado à obtenção de uma satisfação momentânea sem que haja um motivo explicável para esta ação, por exemplo, assistir um filme no cinema, saborear um sorvete, assistir a um jogo de futebol no estádio, viajar nas férias, comprar produtos de última geração ou vestir a moda atual.

Conforme Karsaklian (2013) o marketing está mais posicionado em realizar os desejos dos consumidores, visto a complexidade que agregam ao mercado. É notório ainda, segundo o autor, que a área mercadológica da empresa está diretamente ligada ao cliente, considerando as relações de estudos sobre comportamento do consumidor, satisfação e fidelidade.

\section{Comportamento do Consumidor}

O campo de estudo do comportamento do consumidor desenvolveu-se a partir da década de 50 , onde áreas da administração, economia, psicologia, biologia, filosofia e sociologia, passaram a estudar todo dinamismo de compra das pessoas, com ênfase no que motivava os clientes a consumir (CAMARGO, 2013).

Advento a isto, estudos vem sendo realizado por acadêmicos nas áreas econômicas e administrativas com objetivo de investigar os pressupostos do consumo humano, as empresas passaram a desenvolver ferramentas dentro do marketing para compreender os fatores de influência e os executivos buscaram ganhar conhecimento acerca das tendências do consumidor, visando lucratividade (BLACKWELL, MINIARD e ENGEL, 2013).

Comportamento do consumidor para Las Casas (2017) é definido como um conjunto de fatores psicossociais que emergem nos indivíduos, incentivando ou desestimulando uma compra. Segundo o autor, desde a identificação das necessidades ou desejos, busca por informações das ofertas disponíveis, seleção das melhores opções, realização da compra, consumo, descarte e avaliação pós-compra, o 
consumidor é influenciado por fatores de origem psicológica, culturais, sociais ou familiares.

A figura 01 ilustra de maneira metafórica, o iceberg do consumo humano, representando que o comportamento é uma ação proveniente de um conjunto de motivos que estimulam a realização da compra.

Figura 01: O Iceberg do Consumo Humano.

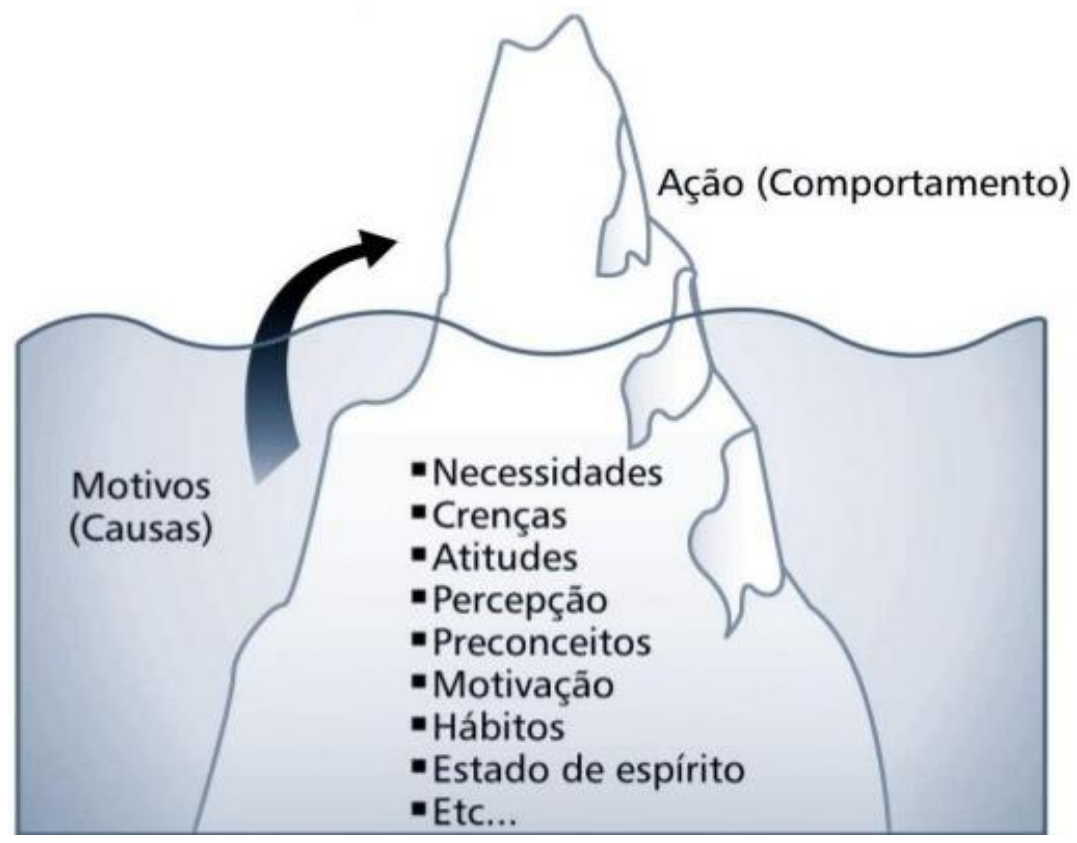

Fonte: Extraído de Samara e Morsch (2012).

Em resumo, o comportamento do consumidor é a interação de fatores que motivam pessoas a comprarem, provocados pelo fenômeno causa versus efeito, apresentados na figura 01 . A causa são todos os atributos norteadores do consumo. O efeito é a ação comportamental resultante em ideias, concepções e experiências durante uma compra, servindo como respaldo para avaliar o desempenho das organizações. A metáfora ainda induz entender que os gestores apenas interpretam o topo do iceberg, os clientes comprando, porém não há visão da parte submersa, ou seja, dos aspectos impulsionadores ao consumo de determinada marca, como exemplo (SAMARA e MORSCH, 2012).

Os fatores psicossociais de origem psicológica influenciam os clientes de forma pessoal, sendo um conjunto de causas, características ou crenças individuais do consumidor, conforme descritas na figura 02, ressaltando que o famoso psicanalista Sigmund Freud foi propulsor no estudo da personalidade humana, enxergando a forma das pessoas comprarem como resultado final de forças que atuam dentro do ser humano, defendendo a existência de energias psíquicas, provindas do meio em que 
os clientes estão inseridos, gerando ações como motivação para consumir, atitude para avaliar uma empresa, percepção de marcas e aprendizagem acerca dos bens ofertados (PETRONIUS, 2016).

Figura 02: Fatores de Origem Psicológica do Consumidor.

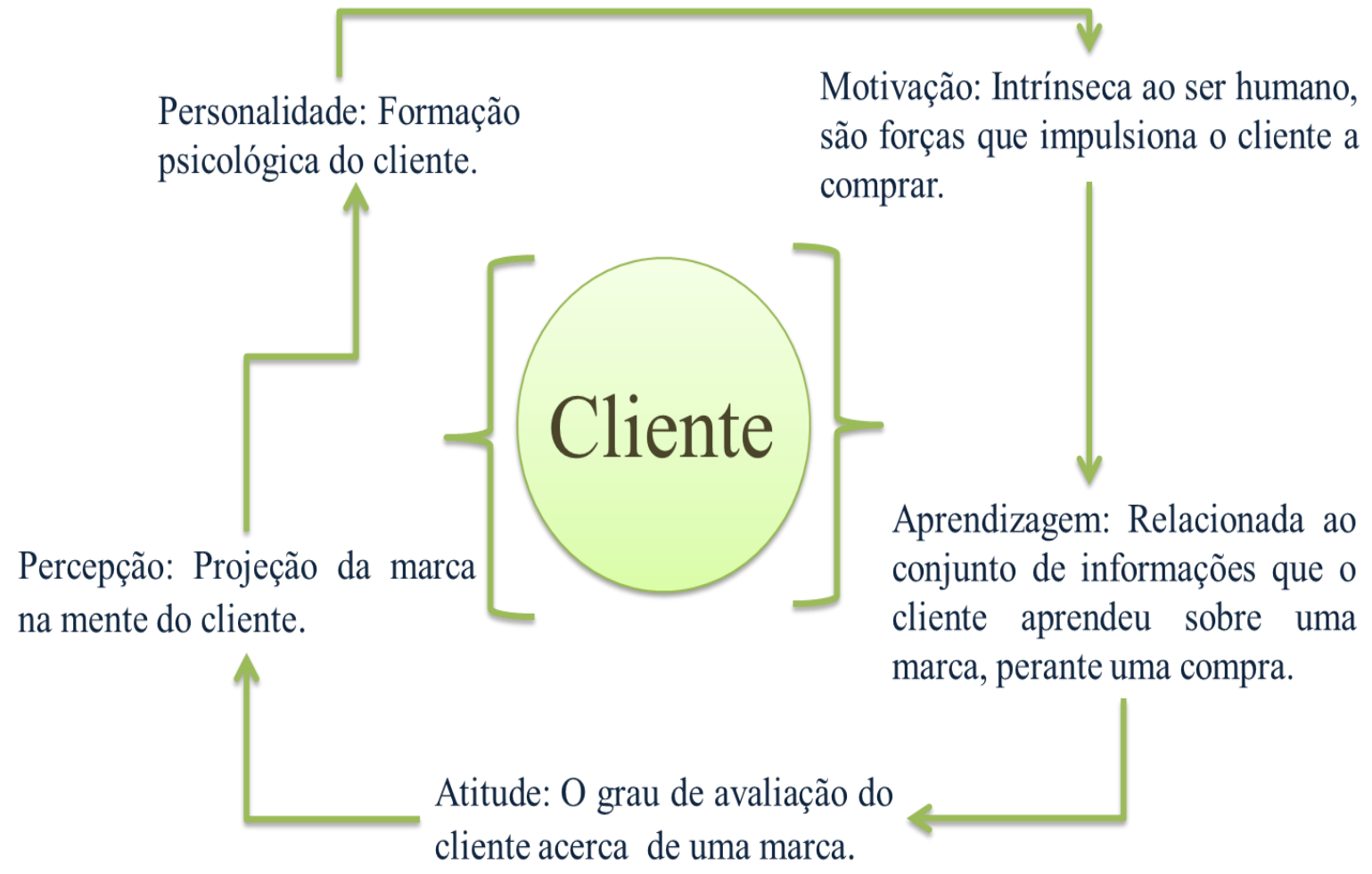

Fonte: Adaptação de Giglio (2010); Graves (2011) e Limeira (2017).

Solomon (2016) discute que os fatores psicológicos são diferentes entre homens e mulheres, colocando em pauta à natureza da receptividade aos estímulos, pois acorrem de forma oposta entre ambos os sexos, exemplo disto é a percepção das cores e tonalidades, mulheres diferenciam melhor as cores em relação aos homens.

Existem diferenças na percepção de compra dos indivíduos ao longo da vida, visto que crianças, adolescentes, jovens, adultos e idosos, possuem seus próprios hábitos consumistas, decorrentes da formação psicológica de cada um, criando então um comportamento de consumo (COBRA, 2015). O autor apresenta que cada empresa atua em um determinado segmento de mercado, contemplando certo público-alvo no qual o marketing necessita conhecer, assim poderá agir em concordância com os hábitos consumistas dos clientes.

Os fatores psicossociais de origem sociais, culturais e familiares, estão relacionados às influências inerentes do ambiente em que as pessoas vivem, onde os consumidores estão inseridos e as 
respectivas interações com o meio social como definidas no quadro 01 , clientes recebem estímulos por meio dos valores agregados, persuadindo a obter noções e preferências de consumo que intriga muitos gestores, visto a possiblidade de exercer descaminhos na hora da compra ou optar por marcas competitivas (PETRONIUS, 2016).

Quadro 01: Fatores de Origem Social, Cultural e Familiar no Consumidor.

\begin{tabular}{|c|l|}
\hline Fatores & \multicolumn{1}{c|}{ Descrição } \\
\hline Sociais & $\begin{array}{l}\text { Em resumo, o cliente é um ser social, vive em grupos e possui renda. Neste } \\
\text { caso o consumidor recebe estímulos do lugar onde vive, interlaçado pela } \\
\text { comunidade, classe social, marketing, situações cotidianas, grupos de } \\
\text { referência mídias, política e tecnologias. Existe um compartilhamento de } \\
\text { alguma característica comum, que ocasiona influências no consumo ao } \\
\text { afetar empresas com a devida aceitação ou rejeição de marcas. }\end{array}$ \\
\hline Fulturais & $\begin{array}{l}\text { Em sinopse, a cultura é uma herança social da humanidade que engloba um } \\
\text { conjunto de manifestações, tradições, crenças, hábitos, costumes e } \\
\text { conhecimentos perpetuados por gerações, possuindo um grau de influência } \\
\text { no consumo das pessoas, desestimulando a entrada ou consumo de marcas. }\end{array}$ \\
\hline $\begin{array}{l}\text { Em síntese, a família é uma das principais influências deterministas no } \\
\text { comportamento do consumidor, levando em conta que os membros do } \\
\text { grupo familiar formam uma sociedade interna dotada de princípios, onde } \\
\text { cada um exerce influência sobre o outro, destacando que na família a } \\
\text { cultura, classe social, escolaridade e religião, provocam estímulos nos } \\
\text { indivíduos em consumir ou não determinadas marcas. }\end{array}$ \\
\hline
\end{tabular}

Fonte: Adaptação de Giglio (2010); Graves (2011) e Limeira (2017).

$\mathrm{Na}$ perspectiva de D’Ângelo (2016) empresas como Amazon e Netflix ganharam reconhecimento no mercado em que atuam ao estudar os consumidores. A Amazon captou dados de clientes, criando em seguida ferramentas para prever o comportamento, a manobra tomada pela empresa tornou-a gigante no e-commerce mundial. A Netflix identificou o comportamento analisando hábitos consumistas em diversos países, logo desenvolveu novas abordagens para os telespectadores, o que a tronou reconhecida no mercado cinematográfico digital como a melhor opção.

Certamente as organizações necessitam compreender os fatores psicossociais, a fim de desenvolver com conformidade bens e serviços conciliados com as necessidades do cliente, haja vista, a importância das empresas projetar na mente do consumidor uma excelente reputação, produto de qualidade, atendimento eficiente, dentre outros fatores positivos a qualquer tipo de negócio, que vise impulsionar o consumidor a comprar e posteriormente, fidelização (KARSAKLIAN, 2013).

O marketing compreendendo os aspectos que compõem o comportamento de consumo das pessoas, mediante ao estudo dos fatores de influência, necessita entender também a cerca da satisfação e fidelização do consumidor, como uma forma de criar conexões entre o cliente e a organização, sendo 
ponto crucial para as empresas obterem sucesso (COBRA, 2015).

\section{Satisfação e Fidelização do Consumidor}

Para Kotler (2013) a satisfação consiste na sensação de prazer ou contentamento, que ocorre quando produtos desenvolvidos suprem com conformidade as expectativas do cliente, resultante da comparação de desempenho percebido com o pressuposto de esperado e realizado ao atender alguma necessidade do consumidor.

De acordo com Las Casas (2017) a fidelização é o grau significativo com que os clientes continuam comprando bens ofertados por uma empresa, na crença de entenderem a benignidade da marca, concepção de comprar e colaborar para o sucesso da organização com a ideia geralmente do não abandono, expectativa no lançamento de novos produtos e criação de valor quando o consumidor sentese acolhido pela empresa.

Os clientes utilizam quesitos como marca, preço, qualidade, status, validade, designer, comodidade e sofisticação para realizar uma compra, não sendo estes estímulos de influência (BLACHWELL, MINIARD E ENGEL, 2013). Segundo os autores, quando os clientes estão satisfeitos usam alguns dos referidos quesitos no processo de compra como ilustra a figura 03 .

Figura 03: Processo de Compra do Consumidor.

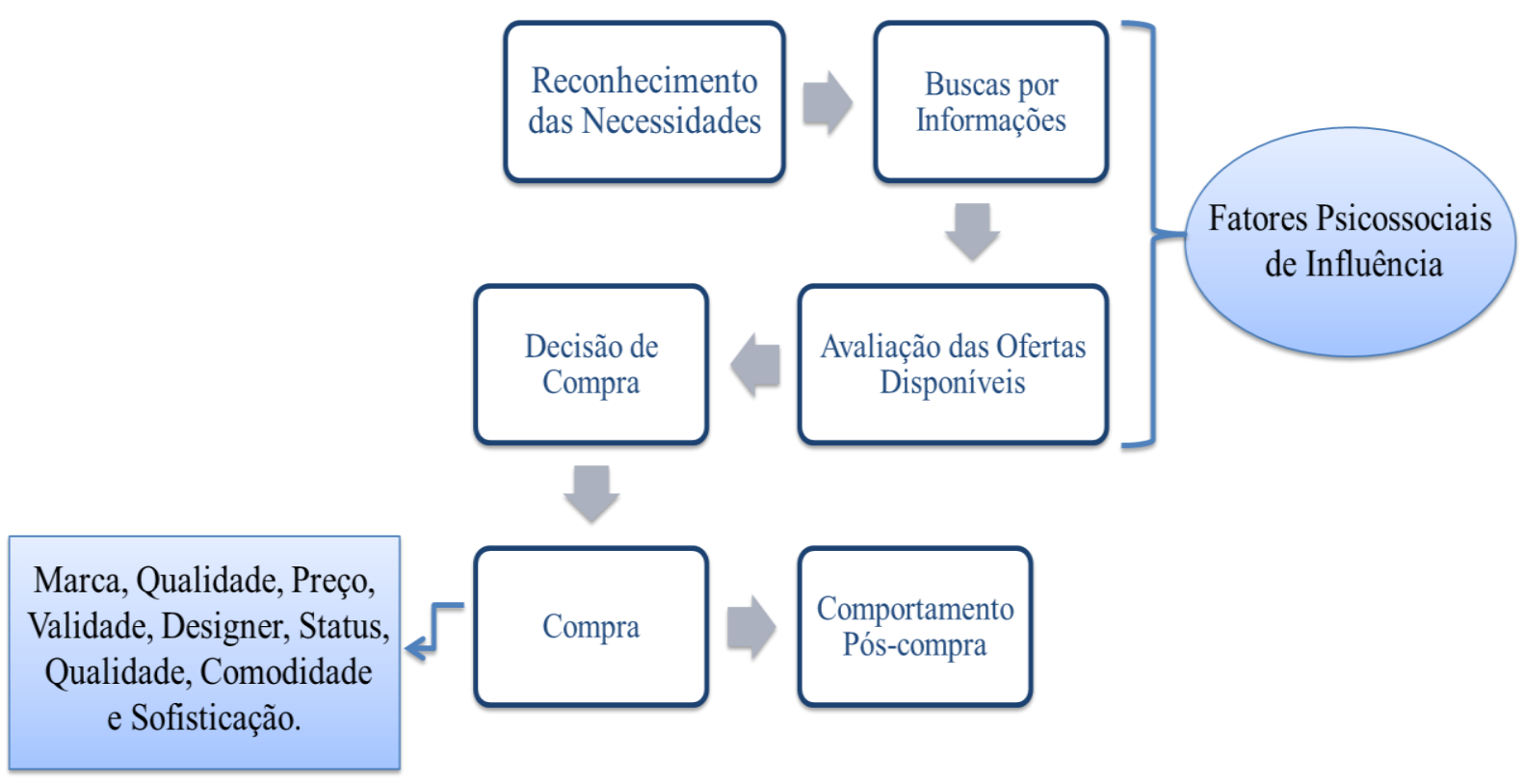

Fonte: Adaptação de Blachwell, Miniard e Engel (2013). 
O processo de decisão da compra do consumidor, descrito na figura 03 acorre na mente do cliente, onde ao transparecer a necessidade ou desejo, o cliente busca informações e avalia as ofertas disponíveis para satisfazer-se, embasados pelos fatores psicossociais de influência. Optando pela compra empossada em quesitos como preço e qualidade, surge o comportamento do consumidor por meio do pós-compra, resultando em uma aceitação ou repudio a marca. Nesse estágio poderá manifestar fidelização, caso a percepção e desempenho do produto esteja conivente com as expectativas e satisfação do cliente (SALOMON, 2016).

O cliente busca bem-estar, caso encontre este aspecto em único lugar, seja empresa, marca, produto ou serviço, fidelizam, um exemplo disto é a Apple, onde os consumidores a fidelizam por diversas questões, incluindo desejos e status (GRAVES, 2012). Sabendo dos pressupostos comportamentais do consumidor, as empresas podem utilizar das ferramentas que o marketing dispõe, a exemplo o teste cego, para atraí novos clientes, obter percepções de satisfação e fidelização dos bens ofertados e investir em outros mercados (GIGLIO, 2010).

Vale salientar que os gestores devem estudar o consumidor, presumindo participação ativa no segmento atuante e vantagens competitivas, enfatizando que muitas empresas chegam ao estado de falência por não conhecerem os clientes, sendo este o principal motivo das empresas existirem (MERLO e CERIBELI, 2014). Oliveira (2010) apresenta o teste cego como uma ferramenta mercadológica capaz de medir o comportamento do consumidor.

\section{Teste Cego}

O marketing disponibiliza várias ferramentas mercadológicas para mensurar as causas do comportamento do consumidor por meio de pesquisas, citando o teste cego como exemplo, visto que é uma pesquisa qualitativa experimental, criada com o intuito de verificar o grau de satisfação e fidelização a um produto ou marca (OLIVEIRA, 2010).

Jones (2015) conjectura o teste cego como um método que possibilita avaliar o grau de aceitação e participação de uma marca, em determinado segmento do mercado competitivo, testando características puras e tangíveis como sabor, textura, aroma, conforto, qualidade e designer, sem as possíveis influências da marca ou marketing, aplicado ao participante da pesquisa, dependendo da natureza do produto, na forma de degustação, geralmente com os olhos vendados.

Oliveira (2015) destaca que o objetivo do teste cego é comparar com concorrentes marcas de produtos a serem lançadas no mercado, como também avaliar percepções de uma já existente, mantendo 
as identidades das respectivas marcas participantes do teste na incógnita, almejando resultados precisos quanto às características comuns.

A percepção dos clientes a deliberada marca ocorre por fatores influenciais, incluindo atributos sensoriais, comportamentais e cognitivos dentro das experiências do consumidor, induzindo preferência ou rejeição de compra pelos estímulos do marketing, quando há incentivos ao consumo (JONES, 2015). $\mathrm{O}$ autor aponta que o teste cego, sucinta compreender o desempenho de um produto sem as devidas induções de escolhas, deixando ao consciente psicológico o direcionamento para esta ação. Com os resultados emitidos, as empresas podem obter noções do mercado atuante, adotar estratégias de marketing, melhorar o produto e tomar decisões que visem o bem-estar do cliente e da organização (OLIVEIRA, 2015).

\section{Metodologia}

O referido artigo baseou-se nas fontes de pesquisa bibliográfica, através de registros em livros e artigos, para obter informações concretas e precisas no âmbito teórico. Caracteriza quanto ao procedimento em levantamento de dados, entrelaçando aspectos de cunho experimental, possuindo uma abordagem quanti-qualitativa, pois nem tudo é quantificável, considerando a realização de teste cego que possui natureza qualitativa (SEVERINO, 2016).

O teste cego aconteceu no dia 15 de setembro de 2018, no centro comercial da cidade de Milagres-CE. 500 consumidores de café participaram da pesquisa por acessibilidade e conveniência (SEVERINO, 2016).

Por intermédio deste teste, avaliou sete marcas de cafés que são comercializadas na cidade em questão, jugando o perfil comportamental relacionado a sabor, aroma e textura, aplicada aos participantes por meio de uma degustação. Cada marca recebeu codinomes de letras do alfabeto, objetivando o anonimato (A, B, C, D, E, F e G). Ressaltando que uma delas correspondia ao café produzido na cidade de Milagres-CE. Os cafés foram preparados por uma especialista no assunto, sendo adicionada a mesma quantidade de pó/massa do produto, $\mathrm{ml}$ de água e açúcar, prevendo que o sabor característico do café prevalecesse e o adocicado não interferisse no resultado.

Os participantes do teste cego responderam 07 perguntas estruturadas, que estavam distribuídas entre abertas e fechadas. No início houve a aplicação de 03 perguntas e ao término 05 . Na sequência com os dados coletados, aconteceu a tabulação pelo software Excel, onde os resultados obtidos foram 
submetidos a análises e discussões, a fim de compreender o conteúdo encontrado, debater e confrontar conhecimentos teóricos apresentados neste estudo.

\section{Análise e Discussão dos Resultados}

A pesquisa foi realizada no centro comercial da cidade de Milagres - Ceará, localizada há 487 km da capital Fortaleza, situada à margem direita do Riacho dos Porcos, próximo a BR 116, com uma população estimada em 2017 de 28.231 habitantes, segundo o Instituto Brasileiro de Geografia e Estatística - IBGE (2016). Conhecida por 'Terra dos Coqueirais', a referida cidade é considerada porta de entrada para o Cariri. As atividades econômicas estão voltadas à agricultura e comércio. Lugar de pessoas hospitaleiras, religiosidade e simplicidade cultural, grupos de congos, culinária genuína, festividades e artesanato popular. Contempla pontos turísticos que englobam igrejas históricas, o Calvário e a Pedra do Chapéu.

O café é uma planta originária da África, trazida ao Brasil por colonizadores, onde o país ocupa a $1^{a}$ posição no ranking de produção e consumo, pautado ainda que tomar café faz parte da cultura brasileira, cotidianamente consumido, destacando um mercado em crescimento, sendo o Nordeste a segunda região que mais produz a commoditie, existindo várias marcas comercializadoras do produto industrializado, atendendo todas as classes sociais, especialmente a $\mathrm{C}$, maior consumidora (SEBRAE, 2011).

Participaram do teste cego 500 pessoas consumidoras e simpatizantes de café, sendo $49 \%$ mulheres e $51 \%$ homens. A faixa etária dos participantes pauteou em 18 a 25 anos $09 \%, 26$ a 35 anos $15 \%, 36$ a 45 anos 25\%, 46 a 55 anos $40 \%$ e 56 a 65 anos 11\%. Houve grande participação do público adulto, somando $65 \%$ entre 36 a 55 anos.

Na sequência, a tabela 01 apresenta o teste cego sobre a Preferência do café.

Tabela 01: Preferência de Café.

\begin{tabular}{c|c}
\hline Preferência de Café & \% Da Preferência \\
\hline Kimimo & $52 \%$ \\
\hline Ojuara & $23 \%$ \\
\hline Spertto & $18 \%$ \\
\hline Pilão & $5 \%$ \\
\hline Santa Clara & $2 \%$ \\
\hline
\end{tabular}

Fonte: Dados da Pesquisa (2018). 
No início do teste cego, foi perguntado se participante era fiel a alguma marca de café, $96 \%$ disseram que sim e 4\% responderam que não. Ao indagar qual era marca de café da preferência do entrevistado, surgiram várias opções como demonstrado na tabela 01.

O interessante é que a marca produzida na cidade em estudo, não aparece como predileta.

Analisando a tabela 01, percebesse que a marca Kimino lidera em termos de preferência, por ser uma marca popular bastante comercializada na cidade de Milagres-CE, seguida pelos cafés Ojuara e Spertto. Neste caso entende-se que a maioria dos consumidores entrevistados está satisfeito, ou seja, os produtos ofertados estão em conformidade com as expectativas dos clientes como menciona Kotler (2013). Questionou-se na sequência, quais atributos ou quesitos os participantes consideravam importante na hora de realizar qualquer compra. As respostas fornecidas estão representadas no gráfico 01.

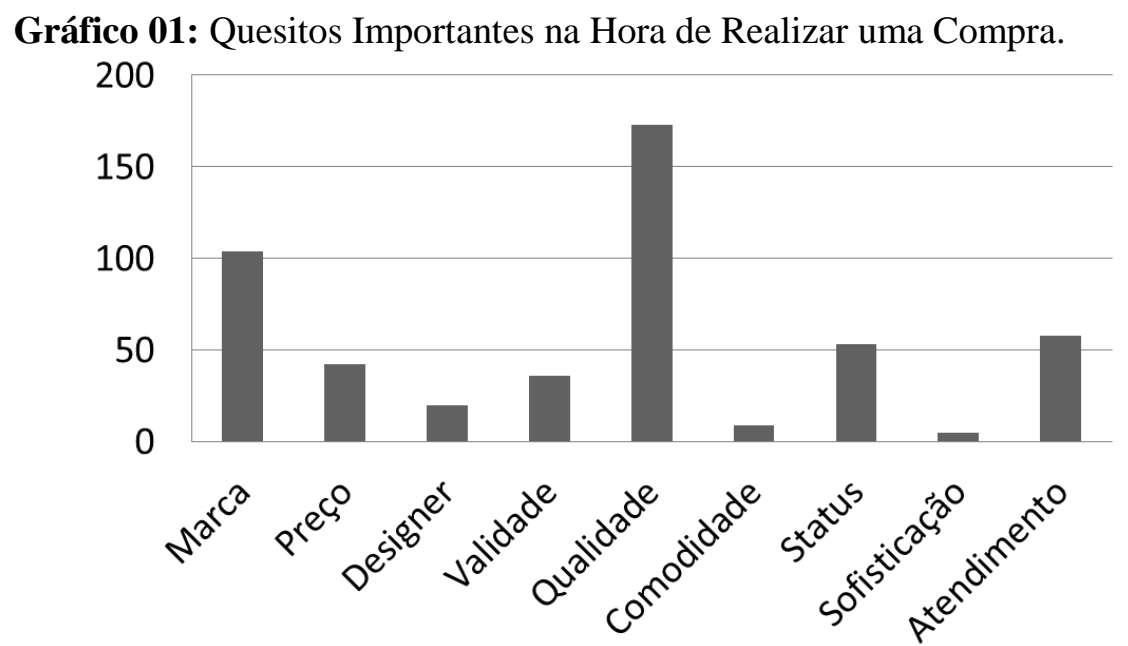

Fonte: Dados da Pesquisa (2018).

Estes quesitos, conforme descritos no gráfico 01, são atributos utilizados pelos consumidores durante o processo de compra, conforme os autores Blachwell, Miniard e Engel (2013). É perceptível que o quesito qualidade prevalece sobre os demais como a opção utilizada na hora de realizar uma compra, presumindo entender que a percepção de consumo evoluiu e o comportamento do consumidor gira em torno do bem-estar, citado por Graves, 2012. A marca aparece logo em seguida, evidenciando a ideia que o cliente compra em função da marca, confirmando a notícia publicada no jornal O Globo em 2017. O status também é dito como um atributo importante, no entanto gera a dúvida se está relacionado à necessidade, desejo ou satisfação pessoal em adquirir um produto ou marca. 
Há um destaque para o atendimento, visto que nenhum autor fala sobre este quesito, porém aparece como um atributo relevante para efetuar uma compra. O preço aparece com baixa incidência, levando a crê que o cliente avalia outros atributos pertinentes ao produto, antes de fechar a compra. Podendo está ligado à renda ou classe social do indivíduo, interferindo diretamente no comportamento do consumidor, em relação aos fatores psicossociais apontados por Petronius (2016). Vale ressaltar que Las Casas (2017) fala sobre fidelização, no ato que Salomon (2016) cita que havendo algum quesito favorável ao cliente, este fideliza a marca, empresa ou produto, surgindo o comportamento do consumidor, envolto em algum fator de influência.

Discutindo acerca de café, foi indagado aos participantes da pesquisa, sobre o que chamava atenção em um bom café. As respostas firmaram em 62\% sabor, $2 \%$ textura, $23 \%$ aroma e $13 \%$ a marca. Sabor, textura e aroma relacionam com a qualidade de um café, quesito este respondido pela maioria como crucial para realizar uma compra. Contudo, de maneira curiosa a marca corresponde um percentual menor, em referencia ao gráfico 01. A explicação para esta ocorrência está no fato do café ser um bem específico, prevalecendo valores culturais de consumo, apontando um fator psicossocial dito por Petronius (2016).

Depois de respondido a estas indagações iniciais, os participantes foram submetidos ao teste cego, no passe que experimentaram os cafés e atribuíram notas, distribuídas em péssimo, regular, bom e ótimo para critérios como sabor, textura e aroma. Em seguida foi perguntado qual o nome da respectiva marca, na opinião destes. Os resultados referentes a sabor, estão descritos no gráfico 02.

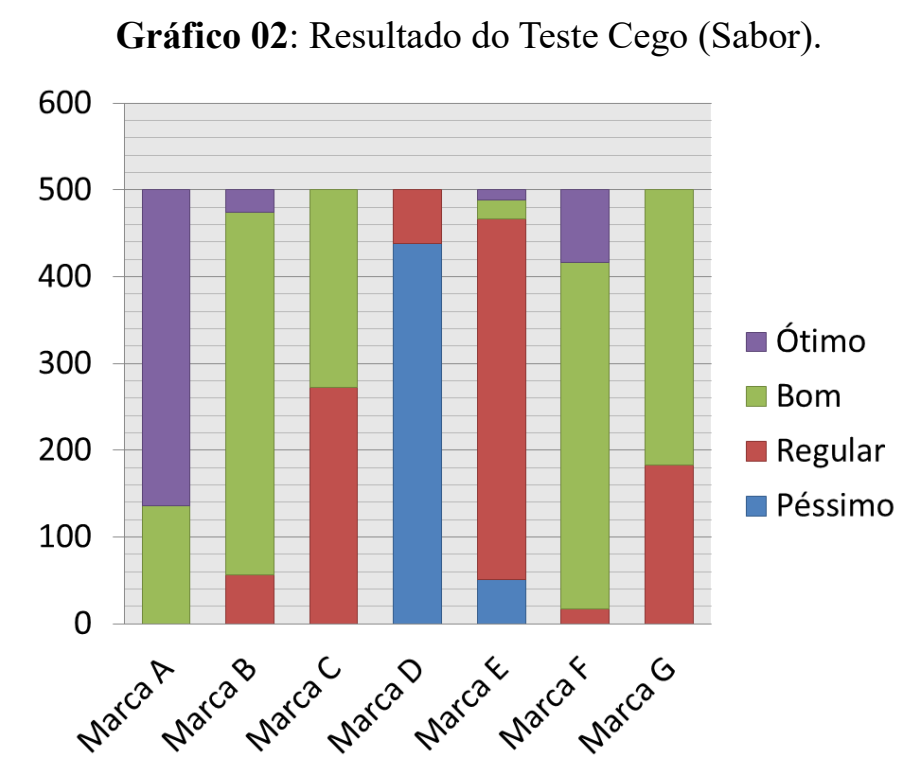

Fonte: Dados da Pesquisa (2018). 
É notória que em questão de sabor ouve uma grande oscilação dos resultados, a marca A obteve notas entre bom e ótimo, destacando-se com relação às demais. Nenhum dos participantes acertou o nome desta marca, que correspondia o café 3 Corações. $O$ curioso que esta marca não aparece como café de preferência, conforme dados descritos na tabela 01 .

A marca B obteve um percentual considerável de nota bom, apenas $27 \%$ dos entrevistados acertaram o nome, que era o café Kimino, marca está que liderou no quesito preferência, no entanto verifica-se um pequeno grau de nota regular. O mesmo caso aplicou-se a marca $\mathrm{F}$, apenas $23 \%$ confirmaram o nome, café Spertto, pontuando como bom na opinião dos participantes, tendo esta marca uma leveza no âmbito regular em comparação a B. Nota que a marca F é uma das preferidas, ocupando terceiro lugar, segundo dados da tabela 01 .

As marcas $\mathrm{C}$ e $\mathrm{G}$ pontuaram entre bom e regular. Em ambas, nenhum dos participantes descobriu o nome da marca, que correspondiam aos cafés Pilão e Santa Clara, respetivamente. A diferença é que foi atribuída a marca $\mathrm{G}$ mais pontos bons com relação a $\mathrm{C}$, enfatizando ainda que a $\mathrm{C}$ apareceu como preferida em quarta posição e $\mathrm{G}$ no ultimo lugar na tabela 01.

A marca D correspondeu ao café produzido na cidade de Milagres-CE, verifica-se então um alto índice de notas péssima, seguido por regular. Foi a única marca que quase todos os participantes acertaram o nome, cerca de $97 \%$ falaram o famoso Palabom. É evidente que este café contém algum sabor característico, facilitando o reconhecimento.

A marca D não incide como preferida, ao analisar os dados da tabela 01. Percebesse então que o consumidor milagrense rejeita à marca. Os motivos desta ocorrência pode esta relacionada à falta de influencia ao consumo e a qualidade insatisfatória do produto, ficando perceptível que a própria marca não estuda ou desconhece os clientes, confirmando a ideia de Merlo e Ceribeli (2014).

O café E recebeu um alto grau de pontos regulares, tendo baixo índice de bom e ótimo, colocando em foco também a parecença de péssimo. Foi o único café que recebeu as quatro notas, pautando um percentual de acerto do nome da marca em $8 \%$. Ojuara era nome deste café, que de acordo com dados da tabela 01 , ocupa a segunda posição na preferência.

O sabor é o elemento mais característico de qualquer café, através deste critério, existe a possibilidade de avaliar a qualidade do produto em estudo. Há uma contradição entre os dados fornecidos pelos participantes na tabela $01 \mathrm{com}$ as do gráfico 02 , onde é nítida que na tabela a marca possui poder de influência, já no gráfico é a qualidade. Outro critério avaliado pelos participantes foi à textura do café, ou seja, a coloração do produto, os resultados captados podem ser observados no gráfico 03.

791 Id on Line Rev. Mult. Psic. V.12, N. 42, p. 779-796, 2018 - ISSN 1981-1179 Edição eletrônica em http://idonline.emnuvens.com.br/id 
Gráfico 03: Resultado do Teste Cego (Textura).

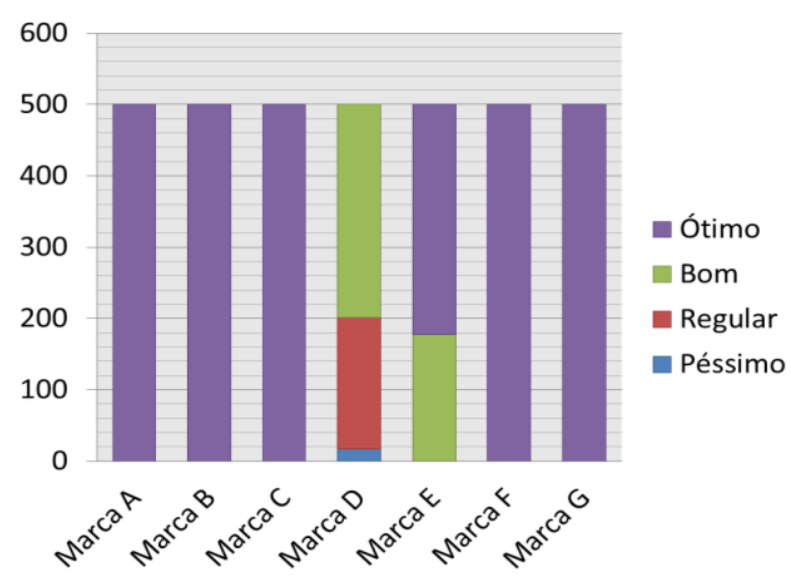

Fonte: Dados da Pesquisa (2018).

As marcas A, B, C, F e G apresentam uma ótima textura como exposto no gráfico 03, na opinião dos participantes. A marca D, café produzido na cidade em estudo, obteve pontos bons, no entanto observa-se a presença de notas regulares e péssimas. A marca $E$ recebeu nota ótima, mas existe a ocorrência de ponto bom. Conclui-se que as marcas atendem ao atributo cor, com exceção da marca $D$, pois abre um leque de questionamentos ao entender o porquê da textura não chamar a atenção, em relação às concorrentes.

Outro critério avaliado foi o aroma, que significa o cheiro liberado pelo produto. O gráfico 04 demonstra as respostas dadas pelos participantes.

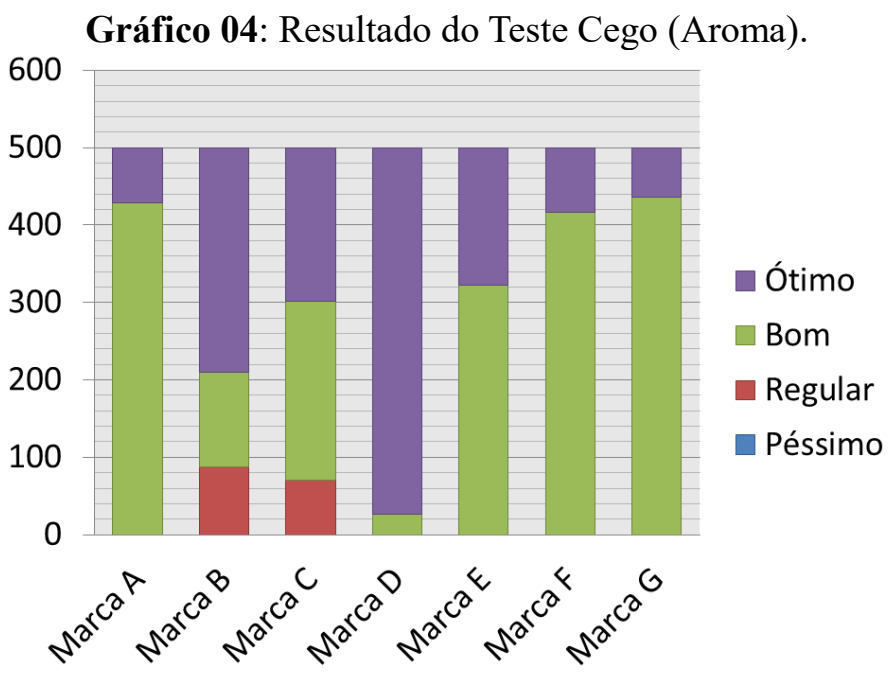

Fonte: Dados da Pesquisa (2018). 
No quesito aroma, observa-se que a marca D surpreendeu, visto resultados dados nos gráficos 02 e 03 , comparando às concorrentes, recebendo ponto ótimo em elevado grau. $\mathrm{O}$ cheiro característico desse café remete a infância de muitos milagrenses. Não é novidade na cidade sentir o cheiro quase todos os meses dos graus de café sendo torado, liberando a fumaça pela chaminé da fábrica e contagiando o município desde 1970, por isso o destaque no critério aroma, remetendo a valores culturais e psicológicos defendidos por Petronius (2016).

No gráfico 04 percebe-se que as marcas A, E, F e G permanecem em mesma instância de avaliação com ponto bom em maior evidência. Já os cafés B e C sucumbem pequenas incidências de notas péssimas, mas remetem índice positivo com bom e ótimo.

Ao termino do teste cego, foi perguntado aos participantes se estes conheciam a marca de café Palabom produzida em Milagres. A resposta teve um percentual de $100 \%$ de sim, concluindo que todos conhecem a marca, mas não são fieis a esta, tendo em vista os resultados obtidos nos gráficos 02 e 03 . Permitindo ainda compreender a percepção dos clientes a destes produtos, sem interferências da marca ou marketing, como menciona Cobra (2015). A tabela 02 demostra a percepção de falas dos participantes com relação ao café Palabom.

Tabela 02: Percepção de Falas Sobre o Café Palabom.

\begin{tabular}{c|c}
\hline Quantidade de participante & Percepção da fala \\
\hline 83 & "Sabor enjoativo" \\
\hline 49 & "Quase não tem gosto de café" \\
\hline 126 & "Pior café" \\
\hline 174 & "Jamais compraria" \\
\hline
\end{tabular}

Fonte: Dados da Pesquisa (2018).

Existe uma percepção negativa com a marca de café Palabom, segundo a tabela 02. Ao analisar as falas ditas, verifica-se uma insatisfação dos consumidores. Em concordância com Giglio (2010) a marca milagrense necessita desenvolver novas formas de fidelizar clientes.

Verificando os resultados encontrados no experimento, nota-se também que esta marca não atende a satisfação ao cliente defendida por Kotler (2013). Levando a crer na metáfora do iceberg, apontado por Samara e Morsch (2012) que refere as empresa ou mercado enxergando apenas os consumidores comprando. Com este teste cego é possível à empresa milagrense desenvolver novas estratégicas de marketing, melhorias no produto e conhecimento do mercado em termos competidor, citados por Oliveira (2015). Sendo plausível a abrangência de ações para fidelização como assinala Graves (2012) e Karsaklian (2013). 


\section{Considerações Finais}

Diante dos procedimentos teóricos e metodológicos utilizados no presente artigo, pode-se considerar que comportamento do consumidor é o conjunto de fatores psicossociais que influenciam a realização de uma compra. Apontando que a fidelização só acontece quando existe a satisfação das necessidades ou desejos dos clientes. Ressaltando ainda que o consumo humano vem evoluindo com o passar do tempo. A marca influencia uma decisão de compra, mas com o experimento rotulado teste cego, é perceptível que sem a interferência da marca o consumidor opta pela qualidade do produto. Verificou-se então que a marca de café produzida na cidade de Milagres-CE é conhecida, mas não é fidelizada por questões inerentes a qualidade.

A problemática pôde ser respondida ao identificar que os clientes são fiéis à marca quando estão satisfeitos com os produtos ou serviços apresentados, considerando que estes estejam expressando qualidade e bem-estar. Fruto da pesquisa, este artigo apresenta dados e mecanismos que permitiram gestores conhecer o mercado de café da referida cidade, além da possibilidade traçar novas metas para fidelizar os consumidores, estudar o perfil dos produtos concorrentes e criar estratégias para captar clientes.

O objetivo geral foi atingindo de maneira plausível, visto que através do teste cego compreendeu a relação de fidelidade dos clientes com a marca de café produzida na cidade em estudo. Em referência aos objetivos específicos, estudou as bases conceituais do comportamento do consumidor, descreveu satisfação e fidelidade do cliente no processo de compra e analisou se os clientes compram um produto em função da qualidade ou marca, compreendendo neste último que a marca influencia a realização da compra, no entanto a qualidade é considerada um fator ou quesito propulsor da venda de um produto ou serviço.

Percebeu com a pesquisa que os consumidores milagrenses conhecem a marca de café fabricada na cidade, todavia rejeitam esta, em função da qualidade não está alinhada aos padrões exigidos no mercado do café. Assim fica aberto para futuros estudos, a necessidade de implantar uma gestão da qualidade na empresa produtora deste citado café.

\section{Referências}

BLACKWELL, Roger; MINIARD, Paul; ENGEL, James. Comportamento do Consumidor. 1. ed. São Paulo: Cengage Learning, 2013. 
CAMARGO, Pedro Celso Julião de. Neuromarketing. A Nova Pesquisa de Comportamento do Consumidor. 1. ed. São Paulo: Atlas, 2013.

COBRA, Marcos. Administração de Marketing no Brasil. 4. ed. Rio de Janeiro: Elsevier, 2015.

D’ÂNGELO, Pedro. Comportamento do Consumidor: Cases de Sucesso. Disponível em: $<$ http://blog.opinionbox.com/comportamento-do-consumidor-cases-de-sucesso/>. Acesso em: 4 de fev. 2018.

GRAVES, Philip. Por Dentro da Mente do Consumidor: O Mito das Pesquisas de Mercado, a Verdade sobre os Consumidores e a Psicologia do consumo. 1. ed. São Paulo: Campus, 2011.

GIGLIO, Ernesto Michelangelo. Comportamento do Consumidor. 4. ed. São Paulo: Cengage Learning, 2010.

IBGE. População e Características Físicas de Milagres - Ceará. Disponível em: <https://cidades.ibge.gov.br/brasil/ce/milagres/panorama>. Acesso em: 16 fev. 2018.

JONES, John Philip. A Publicidade na Construção de Grandes Marcas. 2. ed. São Paulo: NOBEL, 2015.

KARSAKLIAN, Eliane. Comportamento do Consumidor. 2. ed. São Paulo: Atlas, 2013.

KOTLER, Philip. Marketing Essencial: Conceitos, Estratégias e Casos. 14. ed. São Paulo: Pearson Prentice Hall, 2013.

LAS CASAS, Alexandre Luzzi. Marketing: Conceitos, Exercícios e Casos. 9. ed. São Paulo: Atlas, 2017.

LIMEIRA, Tania Maria Vidigal. Comportamento do Consumidor Brasileiro. 2. ed. São Paulo: Saraiva, 2017.

MERLO, Edgar; CERIBELI, Harrison. Comportamento do Consumidor. 1. ed. Rio de Janeiro: LTC, 2014.

O GLOBO. Marcas Vão Além do Preço e Qualidade. São Paulo: Dez. ed. Online, 2017. Disponível em: <https://oglobo.globo.com/economia/marcas-vao-alem-do-preco-qualidade-22167413>. Acesso em: 08 set. 2018.

OLIVEIRA, Roberto Nascimento. A Gestão Estratégica de Marcas Próprias. 2. ed. Rio de Janeiro: Brasport, 2010.

PETRONIUS, Marcos. Consumo Humano. 1. ed. Fortaleza: Popular, 2016.

SAMARA, Beatriz Santos; MORSCH, Marco Aurélio. Comportamento do Consumidor: Conceitos e Casos. 1. ed. São Paulo: Pearson, 2012.

SEBRAE. Boletim Setorial do Agronegócio: Café. 1. ed. Recife: Unidade de Comunicação e Imprensa, 2011. 
SEVERINO, Antônio Joaquim. Metodologia do Trabalho Científico. 24. ed. São Paulo: Cortez, 2016.

SOLOMON, Michael. O Comportamento do Consumidor: Comprando, Possuindo e Sendo. 11. ed. Porto Alegre: Bookman, 2016.

\section{Como citar este artigo (Formato ABNT):}

SILVA, Rangiel Santos Bento; LEITE, Márcia Maria. Comportamento do Consumidor: Um estudo sobre Fidelização com Marcas de Café na Cidade de Milagres-CE. Id on Line Rev.Mult. Psic., 2018, vol.12, n.42, p. 779-796. ISSN: 1981-1179.

Recebido: 19/10/2018;

Aceito: 23/10/2018 